J. Dairy Sci. 95:5203-5212

http://dx.doi.org/10.3168/jds.2012-5317

(C) American Dairy Science Association ${ }^{\circledR}, 2012$.

\title{
The effects of fermented soybean meal on immunophysiological and stress-related parameters in Holstein calves after weaning
}

\author{
M. H. Kim, ${ }^{*}$ C. H. Yun, ${ }^{\star} †$ C. H. Lee, $\neq$ and J. K. Ha ${ }^{* 1}$ \\ *Department of Agricultural Biotechnology and Research Institute for Agriculture and Life Sciences, College of Agriculture and Life Sciences, \\ Seoul National University, Seoul 151-921, Republic of Korea \\ †Center for Agricultural Biomaterials, Seoul National University, 599 Gwanangno, Gwanak-gu, Seoul 151-921, Republic of Korea \\ $\ddagger$ Genebiotech Co. Ltd., Gongju, Republic of Korea
}

\section{ABSTRACT}

The present experiment was conducted to investigate the effects of partial substitution of soybean meal (SBM) with fermented SBM (FSBM) on immunophysiological and stress-related parameters in Holstein calves after weaning. Eighteen Holstein calves were randomly assigned to receive either SBM or FSBM (5\% of SBM was replaced with FSBM) calf starter and calves were weaned at $42 \mathrm{~d}$ of age. It was noted that FSBM contained a lower content of trypsin inhibitor but higher crude protein, amino acids, and small-sized peptides than those of SBM. The group fed FSBM calf starter significantly increased body weight gain and intakes of both feed and milk, when compared with those fed SBM calf starter at 4 wk of age. Calves fed the FSBM calf starter had significantly lower fecal scores than those fed the SBM calf starter during both pre- and postweaning periods. Calves also had better health scores when fed the FSBM calf starter than those fed SBM during the preweaning period. Weaning challenge significantly increased proinflammatory cytokines, tumor necrosis factor $\alpha$, IL-1 $\beta$, and IL-6 levels at $1 \mathrm{~d}$ postweaning (DPW). The TNF- $\alpha$ and IL-6 levels of the SBM group were significantly higher compared with those of the FSBM group at 3 DPW. Acute phase proteins (serum amyloid A and haptoglobin) in the serum were increased after weaning. Concentrations of serum amyloid A and haptoglobin in calves fed FSBM calf starter were significantly lower than those fed the SBM calf starter at 3 and 5 DPW, respectively. The concentration of cortisol was significantly lower in the FSBM group than that of the SBM group at 3 DPW. Weaning stress did not cause drastic changes in the total serum immunoglobulin levels and composition of peripheral lymphocytes. Our results indicate that FSBM may not only improve growth performance, feed intake, and

\footnotetext{
Received January 3, 2012.

Accepted May 14, 2012.

${ }^{1}$ Corresponding author: jongha@snu.ac.kr
}

health conditions during the preweaning period, but also alleviate stress responses, which was indicated by reduced induction of stress hormone, proinflammatory cytokines, and acute phase proteins in Holstein calves after weaning.

Key words: calf, fermented soybean meal, immune, weaning stress

\section{INTRODUCTION}

Domesticated cattle experience various conditions of stress during normal production processes. One of the most widely recognized stressors in cattle production is weaning, which is considered to be one of the key factors affecting subsequent calf health and growth performance. These stressful events are known to be associated with attenuation of immune function (Blecha et al., 1984; Sevi et al., 2001), increased disease susceptibility, decreased feed intake, and impaired growth performance (Shan et al., 2007). For these reasons, active research efforts have been devoted to develop feed additive(s) that could boost immune responses and hopefully at the same time reduce stress responses in weaning calves (Shan et al., 2007). Soybean meal (SBM) is the most commonly used protein source in the animal diet because of its excellent AA profile (Min et al., 2009). And it is the most commonly used supplemental plant proteins for dairy cows due to high palatability with well-balanced essential AA contents (Awawdeh et al., 2007; Mjoun et al., 2010). Therefore, SBM could be considered as an ideal protein source for young animals. However, a variety of antinutritional factors (ANF) have limited its application in the diets of young animals (Li et al., 1990; Jiang et al., 2000; Yoo et al., 2009). A fermentation process reduced ANF in SBM and increased the digestibility of the product, leading to improved overall nutritional quality (Feng et al., 2007; Fujiwara et al., 2008). Furthermore, a variety of essential nutrients, such as vitamins, are also produced during the process (Lee, 1998). Previous studies have reported that fermented SBM (FSBM) improved 
growth performance and reduced diarrheal incident in Escherichia coli-challenged piglets (Kiers et al. 2003; Feng et al. 2007). Therefore, FSBM could be used as a calf starter to improve the health and growth performance of weaned calves. In addition, FSBM could influence the weaning stress response through improved nutritional quality and because it contains various functional molecules. However, data on the effect of FSBM on growth performance, health, and stress responses in calves are not readily available.

The objective of the present study was to evaluate the effects of FSBM (Aspergillus oryzae, fermented) on growth performance, diarrheal incident, changes in immune cells, and acute phase response in weaning calves. We hypothesized that weaning would induce changes in immunophysiological measurements (leukocyte populations, total serum immunoglobulins, and proinflammatory cytokines), acute phase responses [haptoglobin (Hp) and serum amyloid A (SAA)], and stress response (cortisol), and that FSBM in the calf diet would alleviate various stress responses in weaned calves.

\section{MATERIALS AND METHODS}

\section{Preparation of Fermented Soybean Meal}

The fungus (A. oryzae 3.042GB-107) was obtained from Genebiotech Co. Ltd. (Gongju, Korea). Dried soybean meal was soaked in distilled water to maintain a moisture content of $350 \mathrm{~g} / \mathrm{kg}$ overnight. Hydrated SBM was cooked in a steam tank at $65^{\circ} \mathrm{C}$ for $1 \mathrm{~h}$, and then cooled to room temperature $\left(18-20^{\circ} \mathrm{C}\right)$ for $1 \mathrm{~h}$, inoculated with $3 \mathrm{~g}$ of $A$. oryzae $3.042 \mathrm{~GB}-107$ (10,000 counts/g of SBM), mixed, and fermented in a bedpacked incubator for $48 \mathrm{~h}$. After fermentation, fresh fermented samples were dried at 50 to $60^{\circ} \mathrm{C}$ for $3 \mathrm{~d}$. The dried samples were ground and refrigerated until mixed in the diets.

\section{Experimental Animals and Feeding}

All experiments were performed at the Dairy Science Division of the National Institute of Animal Science (Cheonan, Korea). All experimental procedures were reviewed and approved by the Institutional Animal Care and Use Committee on the use of animals at the National Livestock Research Institute (Cheonan, Korea). Eighteen Holstein calves were separated from their mothers, weighed $(39.75 \pm 2.72 \mathrm{~kg}$, mean $\pm \mathrm{SE})$, and moved into individual pens $(1.5 \times 2.5 \mathrm{~m}$; bedded with wood shavings) where they were fed pooled colostrum (protein, mean \pm SE: $13.15 \pm 0.34 \%$; fat, $6.84 \pm 0.21 \%$; lactose, $2.87 \pm 0.04 \%$ ) in the amount of $10 \%$ of BW per day for the first $3 \mathrm{~d}$. The pens had sides composed of solid iron rods with openings in the front and the rear to allow calves free access to the calf starter, chopped mixed grass hay ( $43 \%$ orchardgrass, $43 \%$ tall fescue, and $14 \%$ white clover on a DM basis), and water. The calves were randomly allocated to the dietary treatments (Table 1). Calves of the FSBM group received an FSBM calf starter, in which $5 \%$ of the SBM was replaced with the same amount of FSBM. The respective starter diets were fed ad libitum. Dietary treatment (calf starter) and forage were provided starting at the first and fourth weeks of age, respectively. All calves were fed whole milk using mobile plastic bottles (2-L capacity) fitted with soft rubber nipples. Whole milk was provided in the amount of $20 \%$ of BW per day until $28 \mathrm{~d}$ of age and then, between 29 and $30 \mathrm{~d}$ of age, the amount of milk was gradually decreased to $10 \%$ of BW per day, which was maintained until weaning. All calves were weaned via milk restriction at $42 \mathrm{~d}$ of age. On the morning of the day of weaning, all calves were moved from their individual pens to the assigned group pens ( $\mathrm{n}=2-3$ in each pen) and fed a concentrated mixture and forage without milk, except for some negative control calves $(n=2)$ of each group for weaning challenge.

\section{Chemical Analysis}

Percentages of total protein, fat, and lactose in colostrum were measured by a MilkoScan 104 apparatus (Foss Electric A/S, Hillerød, Denmark). Ingredients and composition of the calf diets are presented in Table 1. Fermented SBM and SBM calf starter were sampled and analyzed for ash by incineration at $550^{\circ} \mathrm{C}$. Protein content $(\mathrm{N} \times 6.25)$ was determined according to the Kjeldahl method. Fat (HCl-fat) was extracted with diethyl ether (Wang et al., 2004). The nutrient compositions of the SBM and FSBM are shown in Table 2. Soybean meal and FSBM were sampled and analyzed for DM by drying at $105^{\circ} \mathrm{C}$ for $5 \mathrm{~h}$. Quantitative analysis of AA in the diet was carried out by cation-exchange high-performance chromatography (Blackbourn, 1978), using an LKB Biochrom (model 4150) autoanalyzer (Biochrom Ltd., Cambridge, UK). The fractionation of SBM and FSBM was carried out with ion-exchange chromatography, using Sp-Sepharose, Mono-Q, or Superdex columns with an automated fast protein liquid chromatography (FPLC) system (Pharmacia AB, Uppsala, Sweden).

\section{BW Gain and Feed Intake}

The intakes of the calf starter, milk, and forage were monitored from 7 to $42 \mathrm{~d}$ of age for individual calves. After weaning, intakes of feed were monitored for each 
Table 1. Ingredients and nutrient composition (\%) of the soybean meal (SBM) and fermented SBM (FSBM) calf starters (CS)

\begin{tabular}{lcc}
\hline Composition & SBM CS & FSBM CS \\
\hline Ingredient (\% of DM) & & \\
Ground corn & 19.9 & 19.9 \\
Ground wheat & 14.3 & 14.3 \\
Molasses & 5.00 & 5.00 \\
Wheat hulls & 15.0 & 15.0 \\
Gluten feed & 10.0 & 10.0 \\
Soybean hulls & 7.0 & 7.0 \\
SBM & 15.4 & 10.4 \\
FSBM & - & 5.00 \\
Corn germ meal & 5.00 & 5.00 \\
Copra meal & 5.00 & 5.00 \\
Salt & 0.50 & 0.50 \\
Ca ${ }_{3}$ PO $\left._{4}\right)_{2}$ & 0.38 & 0.38 \\
CaCo & 1.50 & 1.50 \\
Bio- $\mathrm{Zn}_{\text {Virginiamycin }}$ & 0.01 & 0.01 \\
Premix ${ }^{1}$ (vitamins and trace minerals) & 0.10 & 0.10 \\
NaHCO & 0.30 & 0.30 \\
Analyzed chemical composition (\% as feed) & 0.50 & 0.50 \\
CP & 17.5 & 17.8 \\
Fat & 2.57 & 2.53 \\
Ash & 6.44 & 6.42 \\
\hline
\end{tabular}

${ }^{1}$ Premix supplied the following nutrients per kilogram of mixed feed: vitamin A, 4,400 IU; vitamin D, $733 \mathrm{IU}$; vitamin E, $11 \mathrm{IU} ; \mathrm{CuSO}_{4} \cdot 5 \mathrm{H}_{2} \mathrm{O}$, $85.73 \mathrm{mg}$; zinc oxide, $55 \mathrm{mg} ; \mathrm{MnO}_{2} \cdot \mathrm{H}_{2} 0,55 \mathrm{mg}$; and $\mathrm{MgO}, 1.86 \mathrm{~g}$.

group pen. Overall average BW gain, feed intake (milk, calf starter, and forage), and feed efficiency ( $\mathrm{kg}$ of BW gain/ $\mathrm{kg}$ of total DMI: milk solids, calf starter, and forage) were also examined. Body weight of each calf was recorded every week during the experimental period.

\section{Fecal and Health Scoring}

Overall health condition was evaluated in each calf, based on following scoring systems. Fecal scoring composed of fecal fluidity, consistency, and odor was conducted daily at $0800 \mathrm{~h}$ as follows: for fecal fluidity, normal $=1$, soft $=2$, runny $=3$, and watery $=4$; for fecal consistency, normal $=1$, foamy $=2$, mucouslike $=3$, sticky $=4$, and constipated $=5$; for fecal odor, normal $=1$, slightly offensive $=2$, and highly offensive $=3$. When the fecal score exceeded 3 (average of fluidity, consistency, and odor for 2 consecutive days) or when the calf exhibited other signs of disease, antibiotic therapy (sulfadimethoxine sodium, $55 \mathrm{mg} /$ $\mathrm{kg}$ of BW daily; Green Cross Veterinary Products Co. Ltd., Yongin, Korea) was applied with milk restriction until all clinical signs disappeared or for a maximum of $5 \mathrm{~d}$. Scours were treated with administration of electrolytes (Eltradd, $3 \mathrm{~g} / \mathrm{L}$ in drinking water; Bayer Animal Health Co., Suwon, South Korea). The health score was defined as the mean of the fecal score multiplied by mean of days of antibiotic and electrolyte treatment.

\section{Weaning and Blood Sampling}

Calves were weaned and subsequently grouped at 42 $\mathrm{d}$ of age $[0 \mathrm{~d}$ postweaning (DPW)], except for some negative control calves for weaning treatment. For hematology test and immunoglobulins, blood was collected in $10-\mathrm{mL}$ heparinized tubes (Vacutainer; BD, Plymouth, UK) from the jugular vein at 40 (-2 DPW) and 47 (5 DPW) d of age. Additionally, to examine Hp, SAA, and cortisol, 5-mL blood samples were collected in plain tubes (Vacutainer) at $43(1 \mathrm{DPW})$ and 45 (3 DPW) days of age. Plasma was collected from anticoagulated samples after centrifugation at $1,600 \times g$ at $4^{\circ} \mathrm{C}$ for 15 min and stored at $-80^{\circ} \mathrm{C}$ until subsequent assays were conducted.

\section{Assays to Blood-Associated Parameters}

Neutrophil (NE), lymphocyte (LY), platelet, monocyte, and leukocyte populations in whole blood were determined using an automatic analyzer (Hemavet 850; Drew Scientific, Portsmouth, RI). Total serum immunoglobulin concentrations in the plasma were determined using ELISA kits (Bethyl Laboratory, Montgomery, TX). The concentrations of plasma Hp (Life Diagnostics Inc., West Chester, PA), cortisol (Oxford Biomedical Research Inc., Oxford, MI) and SAA (Tridelta Development Ltd., Maynooth, Co. Kildare, Ireland) were measured using ELISA kits, according to the manufacturer's instructions. Serum concentrations of IL-1 $\beta$ and IL- 6 were assayed using the bovine cytokine screening set (Thermo Scientific, Rockford), with detection ranges of 125 to $2,000 \mathrm{pg} / \mathrm{mL}$ and 312.5

Table 2. Nutrient and peptide compositions of soybean meal (SBM) and fermented SBM (FSBM)

\begin{tabular}{lccc}
\hline Item & SBM & FSBM & SEM \\
\hline DM (\%) & 88.1 & 89.1 & 1.60 \\
Nutrient composition (\% of DM) & & & \\
CP & $47.0^{\mathrm{b}}$ & $52.1^{\mathrm{a}}$ & 0.90 \\
Calcium & 0.25 & 0.53 & 0.01 \\
Phosphorus & 0.8 & 0.72 & 0.02 \\
Trypsin inhibitor (mg/g) & $2.63^{\mathrm{a}}$ & $0.51^{\mathrm{b}}$ & 0.08 \\
AA (\% of protein) & & & \\
Met & 0.64 & 0.71 & 0.03 \\
Lys & 2.82 & 3.20 & 0.03 \\
Thr & 1.82 & 2.15 & 0.02 \\
Leu & $3.54^{\mathrm{b}}$ & $5.42^{\mathrm{a}}$ & 0.04 \\
Val & 2.23 & 2.32 & 0.02 \\
Peptide composition (\% of protein) & & & \\
0-1,000 Da & $6.68^{\mathrm{b}}$ & $37.6^{\mathrm{a}}$ & 1.22 \\
1,000-2,000 Da & $12.8^{\mathrm{b}}$ & $30.1^{\mathrm{a}}$ & 2.67 \\
$2,000-115,000$ Da & $80.4^{\mathrm{a}}$ & $32.1^{\mathrm{b}}$ & 3.42 \\
\hline
\end{tabular}

${ }^{\mathrm{a}, \mathrm{b}}$ Means within a row with different superscript letters differ significantly between SBM and FSBM $(P<0.05)$. 
to $5,000 \mathrm{pg} / \mathrm{mL}$ for IL-1 $\beta$ and IL-6, respectively. Serum samples were measured for absorbance at $450 \mathrm{~nm}$, with reference at $550 \mathrm{~nm}$ without dilution. Serum concentrations of tumor necrosis factor (TNF)- $\alpha$ and IFN- $\gamma$ were assayed using the DuoSet ELISA kit according to the manufacturer's protocol (R\&D Systems Inc., Minneapolis, MN), with detection ranges of 6.25 to $800 \mathrm{pg} /$ $\mathrm{mL}$ and 78 to $10,000 \mathrm{pg} / \mathrm{mL}$ for TNF- $\alpha$ and IFN- $\gamma$, respectively.

\section{Flow Cytometry Analysis}

Lymphocytes $\mathrm{CD} 4^{+}$and $\mathrm{CD} 8^{+}$were quantified by single-color flow cytometry analysis. Cells were harvested and stained $\left(5 \times 10^{5}\right)$ with CD4-APC and CD8APC $(1 \mu \mathrm{g} / \mathrm{mL}$; VMRD Inc., Pullman, WA). After incubating for $30 \mathrm{~min}$ at $37^{\circ} \mathrm{C}$, the cells were washed 3 times with PBS, and differences in the expression of cell surface molecules were detected using a FACSCanto flow cytometer (BD Biosciences, San Jose, CA). All data were further analyzed with FACSDiva software (BD Biosciences).

\section{Statistical Analysis}

Data from hematology cytokines, and acute phase proteins (APP) were analyzed using the Proc Mixed procedure of SAS (SAS Institute, 2001). The model contained the effects of time, diet, and the interaction of time $\times$ diet. When a significant effect of time or diet was found, differences among means were tested using the least significant difference (LSD) procedure of SAS (SAS Institute, 2001). Data from nutrient and peptide compositions of diet were analyzed using a $t$-test. Data from growth performance, feed intake, feed efficiency, health monitoring, total immunoglobulin, and cortisol were analyzed separately at each time point. Data represent mean \pm standard error. Effects were considered significant at $P<0.05$.

\section{RESULTS}

\section{Chemical Composition of Diets}

The chemical compositions of SBM and FSBM calf starters were similar (Table 1). Crude protein in FSBM calf starter was slightly higher than SBM calf starter (17.85 vs. $17.50 \%$, respectively). Nutrient compositions of SBM and FSBM are shown in Table 2. The content of $\mathrm{CP}$ in SBM significantly $(P<0.05)$ increased after fermentation. The content of CP in FSBM was increased by $10.82 \%$ when compared with SBM. In ad- dition, the fermentation process reduced the content of trypsin inhibitor in SBM by $81.48 \%$. The content of AA showed a tendency of elevation, particularly leucine $(P<0.05)$. This result indicates that the fermentation process increased the proportion of small-sized peptides in SBM. Indeed, as shown in Table 2, the proportion of small- $(0-1,000 \mathrm{Da})$ and middle- $(1,000-2,000 \mathrm{Da})$ sized peptides was significantly $(P<0.01)$ increased in FSBM compared with SBM (6.68 vs. $37.69 \%$ and 12.83 vs. $30.15 \%$, respectively). On the contrary, the composition of large-sized peptides $(2,000-115,000 \mathrm{Da})$ was significantly $(P<0.01)$ decreased in FSBM $(80.49$ vs. $32.16 \%)$.

\section{Growth Performance and Feed Intake}

Body weight gains of calves fed FSBM calf starter were significantly $(P<0.05)$ higher than those of calves fed the SBM at 4 wk of age $(0.30$ vs. $0.54 \mathrm{~kg} / \mathrm{d}$; Table $3)$. Calves fed FSBM consumed significantly $(P<0.05)$ more calf starter than did those in the SBM group at 4 to 6 wk of age (2.59 vs. $3.37 \mathrm{~kg}$ ) and the FSBM group had a significantly $(P<0.05)$ higher milk intake than did those in the SBM group at 2 to 4 wk of age $(68.63$ vs. $78.75 \mathrm{~L})$.

Table 3. Body weight gain, feed intake, and feed efficiency in calves fed different calf starters during pre- and postweaning periods

\begin{tabular}{lccc}
\hline & \multicolumn{2}{c}{ Diet $^{1}$} \\
\cline { 2 - 3 } & SBM & FSBM & SEM \\
\hline Item & & & \\
\hline BW gain (kg/d) & 0.39 & 0.24 & - \\
wk 2 & 0.61 & 0.51 & - \\
wk 3 & $0.30^{\mathrm{b}}$ & $0.54^{\mathrm{a}}$ & - \\
wk 4 & 0.49 & 0.60 & - \\
wk 5 & 0.87 & 0.96 & - \\
wk 6 & 0.60 & 0.47 & - \\
wk 7 (postweaning) & & & \\
Calf starter intake (kg/wk) & $2.59^{\mathrm{b}}$ & $3.37^{\mathrm{a}}$ & 0.13 \\
wk 4-6 (preweaning) & 3.43 & 3.24 & 0.14 \\
wk 7 (postweaning) & & & \\
Milk intake (L) & $68.6^{\mathrm{b}}$ & $73.7^{\mathrm{a}}$ & 3.52 \\
wk 2-4 & 48.3 & 47.6 & 3.12 \\
wk 4-6 & & & \\
Total forage intake (g) & 510 & 558 & 22.2 \\
wk 4-6 (preweaning) & 483 & 461 & 21.3 \\
wk 7 (postweaning) & 47.0 & 47.9 & 2.01 \\
Total DMI (kg) & 0.43 & 0.44 & - \\
Feed efficiency & & & \\
\hline
\end{tabular}

a,b Means within a row with different superscript letters differ significantly between groups $(P<0.05)$.

${ }^{1} \mathrm{SBM}=$ soybean meal; FSBM $=$ fermented SBM.

${ }^{2}$ Total DMI $=$ milk solid, starter, and forage DM intake during the experimental period.

${ }^{3}$ Feed efficiency $=$ kilogram of BW gain per kilogram of total DMI during the experimental period. 
Table 4. Effects of different calf starters on fecal scoring and health scoring during pre- and postweaning periods (all data are presented as mean $\pm \mathrm{SE}$ )

\begin{tabular}{lcc}
\hline & \multicolumn{2}{c}{ Diet $^{1}$} \\
\cline { 2 - 3 } Item & SBM & FSBM \\
\hline Fecal scoring & & \\
wk 2-4 (preweaning) & $2.93 \pm 0.2$ & $2.83 \pm 0.4$ \\
wk 4-6 (preweaning) & $3.89 \pm 0.7^{\mathrm{a}}$ & $1.90 \pm 0.5^{\mathrm{b}}$ \\
wk 7 (postweaning) & $2.91 \pm 0.5^{\mathrm{a}}$ & $0.82 \pm 0.2^{\mathrm{b}}$ \\
Health scoring & & \\
wk 2-4 (preweaning) & $3.42 \pm 0.8$ & $3.12 \pm 0.8$ \\
wk 4-6 (preweaning) & $5.12 \pm 1.0^{\mathrm{a}}$ & $3.98 \pm 0.7^{\mathrm{b}}$ \\
wk 7 (postweaning) & $3.12 \pm 0.7$ & $1.59 \pm 0.5$ \\
\hline
\end{tabular}

$\overline{\mathrm{a}, \mathrm{b}}$ Means within a row with different superscript letters differ significantly between groups at each time period $(P<0.05)$.

${ }^{1} \mathrm{SBM}=$ soybean meal; FSBM $=$ fermented $\mathrm{SBM}$.

${ }^{2}$ Fecal score $=$ total scores of fecal consistency, fluidity, and odor.

${ }^{3}$ Health score $=$ fecal score $\times$ mean days of therapy.

\section{Health Scores}

Calves fed the FSBM diet kept better health condition than calves fed SBM. As shown in Table 4, calves fed the FSBM diet had significantly $(P<0.05)$ lower fecal scores at 4 to 6 wk compared with calves fed the SBM $(1.90 \pm 0.5$ vs. $3.89 \pm 0.7$; mean $\pm \mathrm{SE})$. It was noted that fecal scores of calves fed FSBM was significantly $(P<0.05)$ lower than those of the SBM group during the postweaning period $(0.82 \pm 0.2$ vs. $2.91 \pm 0.5$ ). In addition, the FSBM group had fewer days of necessary therapy (data not shown) and lower fecal scores during the preweaning period. But, no difference in health scores during the postweaning period was observed because a calf in FSBM group received continuous therapy for respiratory disease symptoms (data not shown).

\section{Hematology}

As shown in Table 5, the percentage of LY was significantly $(P<0.05)$ decreased at 5 DPW and resulted in elevation of the NE:LY ratio. A significant difference was observed in the NE:LY ratio between the SBM and FSBM diets at 5 DPW. However, significant interaction between time and diet was not observed. The concentration of white blood cells was significantly $(P<0.01)$ increased at $5 \mathrm{DPW}$, but no effect on diet occurred. Calves without weaning did not show significant compositional changes in peripheral blood (data not shown).

\section{Proinflammatory Cytokines}

As shown in Table 6, among proinflammatory cytokines, significant changes in serum concentration of TNF- $\alpha$, IL-1 $\beta$, and IL- 6 were observed after weaning treatment. Weaning treatment significantly $(P<0.05)$ increased concentrations of TNF- $\alpha$, IL1 $\beta$, and IL- 6 at 1 and 3 DPW and these elevated levels returned to initial levels at 5 DPW. But, negative control calves without weaning treatment remained with similar levels of proinflammatory cytokines (data not shown). It was noted that the level of TNF- $\alpha$ and IL-6 in calves fed the SBM calf diet was significantly $(P<0.05)$ higher compared with those in calves fed the FSBM calf diet at 3 DPW

Table 5. Population of neutrophils and lymphocytes in calves fed different calf starters during pre- and postweaning periods (all data are presented as mean $\pm \mathrm{SE}$ )

\begin{tabular}{|c|c|c|c|c|c|}
\hline \multirow[b]{2}{*}{ Variable $^{1}$} & \multicolumn{2}{|c|}{ Treatment $^{2}$} & \multicolumn{3}{|c|}{ Significance $(P \text {-value })^{3}$} \\
\hline & SBM & FSBM & $\mathrm{T}$ & D & $\mathrm{T} \times \mathrm{D}$ \\
\hline \multicolumn{6}{|l|}{ NE $(\%)$} \\
\hline$-2 \mathrm{DPW}$ & $31.7 \pm 1.3$ & $39.4 \pm 2.6$ & & * & \\
\hline $5 \mathrm{DPW}$ & $44.1 \pm 4.6$ & $38.1 \pm 2.6$ & & & \\
\hline \multicolumn{6}{|l|}{ LY $(\%)$} \\
\hline$-2 \mathrm{DPW}$ & $61.5 \pm 2.8$ & $58.1 \pm 4.5$ & & & \\
\hline 5 DPW & $51.6 \pm 4.0$ & $52.6 \pm 4.5$ & $*$ & & \\
\hline \multicolumn{6}{|l|}{ NE:LY ratio } \\
\hline$-2 \mathrm{DPW}$ & $0.53 \pm 0.07$ & $0.68 \pm 0.10$ & & & \\
\hline $5 \mathrm{DPW}$ & $0.91 \pm 0.08$ & $0.72 \pm 0.06$ & $*$ & * & 0.056 \\
\hline \multicolumn{6}{|l|}{$\mathrm{WBC}\left(10^{9} / \mathrm{L}\right)$} \\
\hline$-2 \mathrm{DPW}$ & $7.65 \pm 0.5$ & $7.65 \pm 1.0$ & & & \\
\hline 5 DPW & $8.95 \pm 1.2$ & $8.66 \pm 1.0$ & $* *$ & & \\
\hline
\end{tabular}

${ }^{1} \mathrm{NE}=$ neutrophil; $\mathrm{LY}=$ lymphocyte; DPW $=$ days postweaning $(0 \mathrm{DPW}=$ day of weaning treatment, $42 \mathrm{~d}$ old); WBC $=$ white blood cells.

${ }^{2} \mathrm{SBM}=$ soybean meal; FSBM $=$ fermented SBM.

${ }^{3} \mathrm{~T}=$ time effect; $\mathrm{D}=$ dietary effect; $\mathrm{T} \times \mathrm{D}=$ interaction between time and diet effect.

${ }^{*} P<0.05 ;{ }^{* *} P<0.01$. 
KIM ET AL.

Table 6. Effects of different calf starters on proinflammatory cytokine levels (mean $\pm \mathrm{SE}$ ) in calves after weaning challenge

\begin{tabular}{|c|c|c|c|c|c|}
\hline \multirow[b]{2}{*}{ Variable $^{1}$} & \multicolumn{2}{|c|}{ Treatment $^{2}$} & \multicolumn{3}{|c|}{ Significance $^{3}$} \\
\hline & SBM & FSBM & $\mathrm{T}$ & $\mathrm{D}$ & $\mathrm{T} \times \mathrm{D}$ \\
\hline \multicolumn{6}{|c|}{ TNF- $\alpha(\mathrm{pg} / \mathrm{mL})$} \\
\hline$-2 \mathrm{DPW}$ & $303 \pm 27.2$ & $278 \pm 41.3$ & & & \\
\hline $1 \mathrm{DPW}$ & $420 \pm 83.4$ & $579 \pm 84.4$ & * & & \\
\hline $3 \mathrm{DPW}$ & $941 \pm 91.2^{\mathrm{a}}$ & $441 \pm 98.5^{\mathrm{b}}$ & $*$ & * & * \\
\hline $5 \mathrm{DPW}$ & $406 \pm 99.8$ & $273 \pm 84.5$ & & & \\
\hline \multicolumn{6}{|c|}{ IL-1 $\beta(\mathrm{pg} / \mathrm{mL})$} \\
\hline$-2 \mathrm{DPW}$ & $30.2 \pm 5.2$ & $25.1 \pm 4.2$ & & & \\
\hline $1 \mathrm{DPW}$ & $44.1 \pm 5.4$ & $46.8 \pm 5.0$ & * & & \\
\hline $3 \mathrm{DPW}$ & $39.5 \pm 9.2$ & $40.2 \pm 8.2$ & & & \\
\hline $5 \mathrm{DPW}$ & $30.1 \pm 4.2$ & $28.2 \pm 6.4$ & & & \\
\hline \multicolumn{6}{|c|}{ IL-6 (pg/mL) } \\
\hline$-2 \mathrm{DPW}$ & $34.3 \pm 5.4$ & $35.1 \pm 6.2$ & & & \\
\hline 1 DPW & $53.3 \pm 4.4$ & $56.1 \pm 5.9$ & $*$ & & \\
\hline $3 \mathrm{DPW}$ & $69.4 \pm 6.1$ & $40.4 \pm 4.1$ & $*$ & * & * \\
\hline $5 \mathrm{DPW}$ & $40.1 \pm 5.7$ & $28.1 \pm 4.3$ & & & \\
\hline \multicolumn{6}{|c|}{$\operatorname{IFN}-\gamma(\mathrm{pg} / \mathrm{mL})$} \\
\hline$-2 \mathrm{DPW}$ & $11.1 \pm 2.75$ & $13.4 \pm 3.75$ & & & \\
\hline 1 DPW & $10.3 \pm 1.41$ & $11.3 \pm 1.41$ & & & \\
\hline 3 DPW & $7.2 \pm 1.19$ & $10.2 \pm 2.21$ & & & \\
\hline $5 \mathrm{DPW}$ & $8.5 \pm 2.53$ & $8.1 \pm 1.33$ & & & \\
\hline
\end{tabular}

${ }^{a, b}$ Means within a row with different letters differ significantly between groups $(P<0.05)$.

${ }^{1} \mathrm{TNF}=$ tumor necrosis factor; DPW $=$ days postweaning $(0 \mathrm{DPW}=$ day of weaning treatment, $42 \mathrm{~d}$ old $)$.

${ }^{2} \mathrm{SBM}=$ soybean meal; FSBM $=$ fermented SBM

${ }^{3} \mathrm{~T}=$ time effect; $\mathrm{D}=$ dietary effect; $\mathrm{T} \times \mathrm{D}=$ interaction between time and diet effect.

$* P<0.05$.

(941.8 vs. $441.4 \mathrm{pg} / \mathrm{mL} ; 69.46$ vs. $40.41 \mathrm{pg} / \mathrm{mL}$ ). Although the serum concentration of IL- $1 \beta$ was increased at $1 \mathrm{DPW}$, no significant dietary effect and interaction was observed. No significant changes in IFN- $\gamma$ levels were observed after weaning challenge.

\section{Serum Proteins and Cortisol}

Our results showed that total serum IgG and $\operatorname{IgA}$ concentrations were influenced by diet but not by weaning. Total serum IgG levels were significantly $(P$ $<0.05)$ higher in the SBM group as compared with the FSBM group at both -2 and 5 DPW (Figure 1). Interestingly, weaning affected the level of SAA and the concentration of SAA was significantly $(P<0.05)$ increased at 3 DPW (Table 7 ). In addition, it was noted that SAA levels of the SBM group were significantly $(P<0.05)$ higher than those of the FSBM group at the same time. Weaning also induced an increase in the concentration of $\mathrm{Hp}$ in calves fed both the SBM and FSBM diets (Table 7). However, the pattern of the Hp changes was different between the 2 groups. Calves fed the FSBM diet demonstrated a drastic elevation in the Hp level $(>50 \mu \mathrm{g} / \mathrm{mL})$ earlier than calves fed the SBM diet (1 vs. 3 DPW); therefore, the Hp level of the FSBM group was significantly $(P<0.05)$ higher than that of the SBM group at 1 DPW (18.83 vs. $83.44 \mu \mathrm{g} /$
$\mathrm{mL}$ ). After that, elevated Hp levels in calves fed FSBM returned to baseline levels earlier than the SBM group at 5 DPW (24.74 vs. $96.38 \mu \mathrm{g} / \mathrm{mL})$. It is noteworthy that weaning increased the cortisol concentrations in both groups, but was more pronounced in calves fed SBM, with a significant $(P<0.05)$ increase occurring at 3 DPW (Figure 2). Negative-control calves of both groups did not show significant changes in cortisol and APP (data not shown).

\section{Composition of Peripheral T Lymphocytes}

Stress could affect the composition of lymphocytes in the peripheral blood. Therefore, the percentage change in composition $(\%)$ of $\mathrm{CD}^{+}, \mathrm{CD} 8^{+}$, and their ratio in peripheral blood was investigated to determine the effects of the FSBM diet on weaning stress. However, no significant changes in $\mathrm{CD} 4^{+}, \mathrm{CD} 8^{+}$, or $\mathrm{CD} 4^{+} / \mathrm{CD} 8^{+}$ cells were observed (Table 8).

\section{DISCUSSION}

In the present study, we have shown that the FSBM calf diet could not only improve health conditions but also alleviated production of potential stress responserelated parameters, including cortisol, APP, and serum proinflammatory cytokines. The fermentation process 

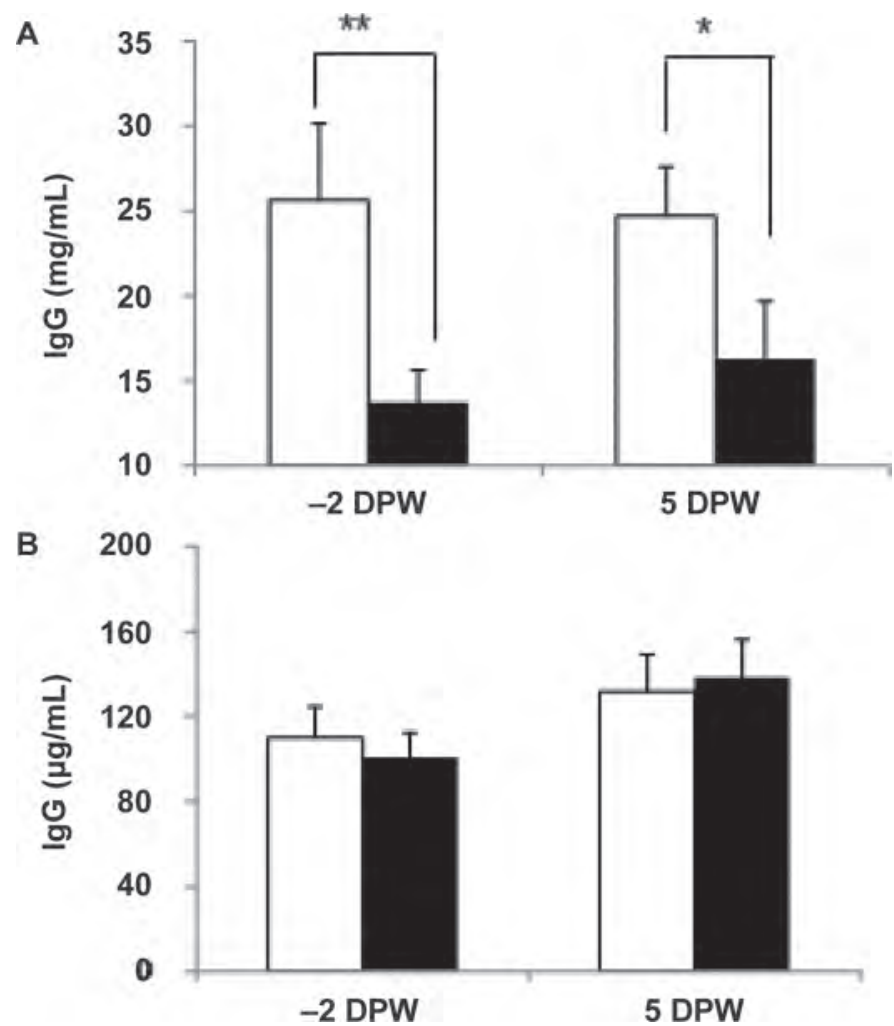

Figure 1. Changes in total serum $\operatorname{IgG}(\mathrm{A})$ and $\operatorname{IgA}(\mathrm{B})$ in neonatal calves fed soybean meal (SBM) or fermented SBM (FSBM) starter. The white bar indicates a group of calves fed the SBM diet and the black bar indicates calves fed the FSBM diet. Means with different symbols differ significantly between groups $\left({ }^{*} P<0.05\right.$; $\left.{ }^{* *} P<0.01\right)$. $\mathrm{DPW}=$ days postweaning. Error bars represent the SE.

induced changes in the nutritional characteristics of SBM. For instance, CP was increased after the fermentation of SBM. This could be explained by decreased

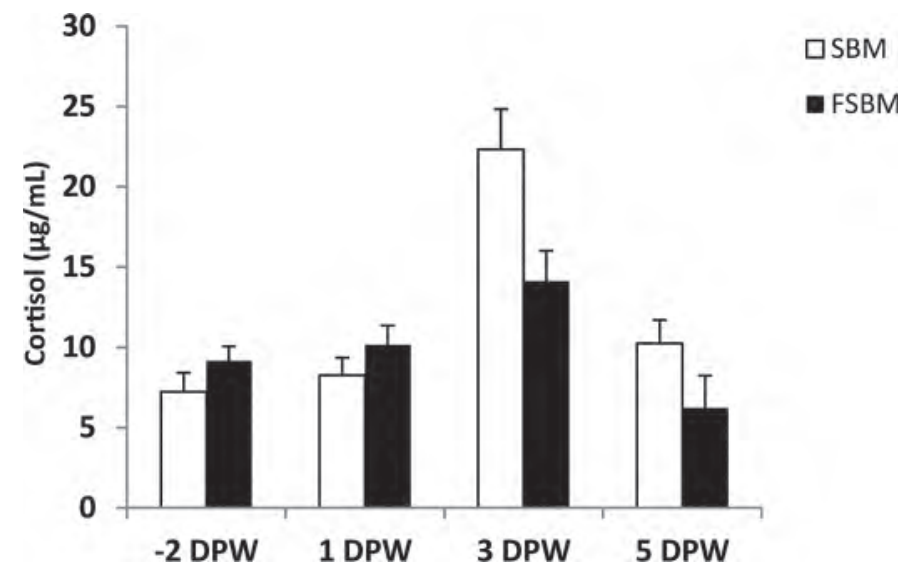

Figure 2. Change in serum cortisol level in calves fed different calf starters. The white bar indicates a group of calves fed the soybean meal (SBM) diet and the black bar indicates calves fed the fermented SBM (FSBM) diet. * indicates that means between the 2 dietary groups are significantly different at $P<0.05 . \mathrm{DPW}=$ days postweaning. Error bars represent the SE.

carbohydrate content after fermentation (Hong et al., 2004). In addition, our study demonstrated that the fermentation process reduced the size of peptides and subsequently reduced the content of trypsin inhibitors in SBM protein and, therefore, improved overall nutritional quality. Hong et al. (2004) also found that fermentation with $A$. oryzae resulted in reduced trypsin inhibitor contents and the size of SBM.

Previous studies have demonstrated the growth-promoting effects by total (Feng et al., 2007) and partial (Kim et al., 2005) substitutions of SBM with FSBM in piglets, which resulted in a higher level of essential nutrients, such as AA and vitamins together with the elimination of some ANF from the SBM during fer-

Table 7. Effects of different calf starters on acute phase protein levels (mean $\pm \mathrm{SE}$ ) in calves after weaning challenge

\begin{tabular}{|c|c|c|c|c|c|}
\hline \multirow[b]{2}{*}{ Variable } & \multicolumn{2}{|c|}{ Treatment $^{1}$} & \multicolumn{3}{|c|}{ Significance $^{2}$} \\
\hline & $\mathrm{SBM}$ & FSBM & $\mathrm{T}$ & $\mathrm{D}$ & $\mathrm{T} \times \mathrm{D}$ \\
\hline \multicolumn{6}{|c|}{ Serum amyloid A $(\mu \mathrm{g} / \mathrm{mL})$} \\
\hline$-2 \mathrm{DPW}^{3}$ & $19.2 \pm 3.1$ & $21.0 \pm 2.3$ & & & \\
\hline $1 \mathrm{DPW}$ & $33.4 \pm 2.1$ & $28.2 \pm 3.4$ & & & \\
\hline $3 \mathrm{DPW}$ & $65.5 \pm 5.7^{\mathrm{a}}$ & $33.6 \pm 3.5^{\mathrm{b}}$ & $*$ & $*$ & $*$ \\
\hline $5 \mathrm{DPW}$ & $49.6 \pm 3.1$ & $29.7 \pm 1.7$ & $*$ & $*$ & \\
\hline \multicolumn{6}{|c|}{ Haptoglobin $(\mu \mathrm{g} / \mathrm{mL})$} \\
\hline$-2 \mathrm{DPW}$ & $7.07 \pm 2.1$ & $6.29 \pm 1.3$ & & & \\
\hline $1 \mathrm{DPW}$ & $18.8 \pm 5.9^{\mathrm{b}}$ & $88.4 \pm 22.7^{\mathrm{a}}$ & $*$ & $* *$ & $*$ \\
\hline $3 \mathrm{DPW}$ & $67.7 \pm 19.9$ & $93.3 \pm 21.1$ & ** & & \\
\hline $5 \mathrm{DPW}$ & $96.3 \pm 11.2^{\mathrm{a}}$ & $24.7 \pm 9.7^{\mathrm{b}}$ & $*$ & ** & $*$ \\
\hline
\end{tabular}

${ }^{\mathrm{a}, \mathrm{b}}$ Means within a row with different letters differ significantly between groups $(P<0.05)$.

${ }^{1} \mathrm{SBM}=$ soybean meal; FSBM $=$ fermented SBM.

${ }^{2} \mathrm{~T}=$ time effect; $\mathrm{D}=$ dietary effect; $\mathrm{T} \times \mathrm{D}=$ interaction between time and diet effect.

${ }^{3} \mathrm{DPW}=$ days postweaning $(0 \mathrm{DPW}=$ day of weaning treatment, $42 \mathrm{~d}$ old $)$.

${ }^{*} P<0.05 ;{ }^{* *} P<0.01$. 
Table 8. Changes in peripheral lymphocyte subsets in calves fed a soybean meal (SBM) and a fermented SBM (FSBM) diet between pre- and postweaning (results shown are mean $\pm \mathrm{SE}$ )

\begin{tabular}{lccccc}
\hline & \multicolumn{2}{c}{ SBM } & & \multicolumn{2}{c}{ FSBM } \\
\cline { 2 - 3 } \cline { 5 - 6 } Lymphocyte & $-2 \mathrm{DPW}^{1}$ & $5 \mathrm{DPW}$ & & -2 DPW & 5 DPW \\
\hline CD4 (\%) & $14.0 \pm 2.7$ & $16.7 \pm 2.4$ & & $12.1 \pm 3.7$ & $13.2 \pm 3.2$ \\
CD8 (\%) & $5.63 \pm 1.4$ & $5.09 \pm 2.0$ & & $8.31 \pm 2.2$ & $5.99 \pm 2.0$ \\
CD4:CD8 & $2.49 \pm 0.7$ & $3.28 \pm 0.3$ & & $1.45 \pm 0.7$ & $2.21 \pm 0.8$ \\
\hline
\end{tabular}

${ }^{1} \mathrm{DPW}=$ days postweaning $(0 \mathrm{DPW}=$ day of weaning treatment, $42 \mathrm{~d}$ old $)$.

mentation (Lee, 1998). Improved growth response by partial replacement of FSBM in the present study may also have occurred through a similar mechanism and, indeed, the FSBM had higher protein and AA contents relative to the SBM. In addition, intake of calf starter and milk was higher in calves fed FSBM calf starter. On the other hand, fermentation of SBM reduced the amount of large molecular proteins and ANF, such as trypsin inhibitor, clearly indicating improved nutritional quality of the FSBM.

Interestingly, calves fed the FSBM diet revealed better health conditions (e.g., lower fecal score) than those of calves fed the SBM diet. In accordance with our results, previous studies have reported that calves fed fermented products had a lower incidence of diarrhea (Kalavi et al., 1996; Karmini et al., 1997; Chu et al., 2011). Because FSBM was prepared through microbial fermentation, it is certain that some of the ANF were eliminated and that proteins were partially digested to smaller sizes, as shown in Table 2. Together with the likelihood of the production of vitamins and other unknown growth-promoting compounds, it is plausible that calves fed the FSBM diet received more nutrients, leading to better growth performance, as compared with calves fed the SBM calf starter during the preweaning period. Consequently, beneficial effects of the FBM diet on growth performance could be explained, as improved nutritional quality by the fermentation process contributed to maintain better health status and improved growth performance.

Leukocyte populations have been suggested as potential biomarkers of physiological stress and disease susceptibility in animals (Church and Hudson, 1999; Kang et al., 2011). Anderson et al. (1999) reported that the NE:LY ratio was increased when animals were challenged with dexamethasone. Previous studies have reported an increase in the NE:LY ratio in weaned calves up to $14 \mathrm{~d}$ (Church and Hudson, 1999) due to glucocorticoids (Hickey et al., 2003), suggesting glucocorticoids as a contributing factor to the alteration of the NE:LY ratio. Our study also showed that weaning increased the NE:LY ratio in calves at $5 \mathrm{DPW}$. Although no sig- nificant difference between diets was observed, calves fed the SBM calf starter showed numerical elevation of the NE:LY ratio, whereas this pattern was not observed in calves fed the FSBM calf starter. A possibility exists that calves fed the SBM calf starter responded to a greater extent to weaning stresses than those fed the FSBM diet.

Total serum IgG and IgA concentrations in both groups were not influenced by weaning, which is in accordance with previous reports that demonstrated that abrupt weaning affected the cell-mediated immunity rather than the humoral immunity of weaned calves (Mackenzie et al., 1997; Hickey et al., 2003). It is noteworthy that although total serum $\operatorname{IgG}$ and $\operatorname{Ig}$ A were not influenced by weaning, they were influenced by diet. The possibility exists that the immune responses of calves fed the SBM diet were influenced by a variety of factors (Li et al., 1990; Liu et al., 2007; Kim et al., 2010), leading to elevated serum IgG. It is well known that a variety of ANF, such as trypsin inhibitor, lectins, and soybean globulins, can induce hypersensitivity responses in young animals. In our previous study, total serum IgG levels of calves fed the SBM diet were higher than those of the calves fed the FSBM diet at 4, 5, and 6 wk of age (Kim et al., 2010).

Acute phase proteins refer to a group of hepatic glycoproteins that are stimulated by inflammatory mediators and induced as an initial reaction to infection, inflammation, or trauma in animals (Marinkovic et al., 1989). Therefore, monitoring the circulating concentration of APP is important in evaluation of animal health (Hickey et al., 2003). In addition, APP might be useful biomarkers of the stress responses in calves because, in response to stress stimuli, blood concentrations of APP increased (Conner et al., 1988). Murata (2007) suggested that, although APP have been considered to be a marker of inflammation or infection (or both), an essential linkage exists between noninflammatory stress and the acute phase response. Triggered by inflammatory signals (predominantly cytokines), stressed animals exhibit a nonspecific elevation in the concentrations of APP in circulation. In particular, inflammatory cyto- 
kines (IL-1, IL-6, and TNF- $\alpha$ ) are considered mediators of the immunological and pathological responses to stress and infection (Warren et al., 1997). Therefore, we investigated profiles of serum proinflammatory cytokines and APP after weaning stress challenge. In the present study, weaning increased TNF- $\alpha$, IL-1 $\beta$, and IL-6 concentrations in the serum of calves. More importantly, calves fed the SBM diet showed higher levels of TNF- $\alpha$ and IL-6 than did the FSBM group at 3 DPW. These results suggest that weaning as a stressor could have induced production of proinflammatory cytokines and the FSBM calf diet might have alleviated stressinduced proinflammatory cytokine production after weaning treatment. We also compared levels of serum APP in calves between the SBM and FSBM groups after weaning treatment. Haptoglobin and SAA are considered to be representative APP in cattle. It is well known that proinflammatory cytokines (IL-1, IL-6, and $\mathrm{TNF}-\alpha$ ) can induce acute phase response (Heegaard et al., 2000; Murata, 2007) It is noteworthy that during an acute phase response, bovine $\mathrm{Hp}$ can increase 50 to 100 fold, whereas SAA changes moderately during an acute phase response and increases approximately 2 to 5 fold (Heegaard et al., 2000). Although weaning induced an increase in $\mathrm{Hp}$ in both SBM and FSBM diet groups, different patterns of the Hp changes were observed in the present study. Calves fed the FSBM diet showed drastic elevation of the Hp level earlier than did calves fed the SBM diet. Additionally, elevated Hp levels in calves fed the FSBM diet returned to baseline levels earlier than those fed the SBM diet. This is a clear indication that calves fed the FSBM diet adapted to weaning conditions better than those fed the SBM starter diet. Weaning also affected SAA levels. It is noteworthy that calves fed the FSBM diet demonstrated lower SAA production after the weaning challenge, with lower proinflammatory cytokine levels. These results may suggest that the FSBM calf starter alleviates acute phase responses caused by weaning stress and these alleviating effects might be caused by reduced proinflammatory cytokine production.

Elevated circulating glucocorticoid and cortisol concentrations in the blood are hallmarks of stress in livestock. As stress is known to induce the hypothalamicpituitary-adrenal axis, it is reasonable to assume that cortisol levels can be a reliable indicator of a stress response (Beerda et al., 1996; Queyras and Carosi, 2004). In the present study, weaning induced an increase in cortisol in both groups, but more pronounced elevations were seen in calves fed the SBM calf starter. At 3 DPW, calves fed the SBM calf diet had higher cortisol levels than those of calves fed FSBM.

\section{CONCLUSIONS}

Calves fed the FSBM diet had improved feed intake, growth performance, and health conditions during the preweaning period, and lowered levels of stress-related serum variables (proinflammatory cytokines, APP, and cortisol) after weaning. Fermented SBM may be beneficial in alleviating stress responses in calves undergoing a weaning challenge.

\section{ACKNOWLEDGMENTS}

This work was supported by the Korea Science and Engineering Foundation (KOSEF, Daejeon, South Korea) and granted by the Korean government (MEST; R01-2008-000-10854-0).

\section{REFERENCES}

Anderson, B. B., D. L. Watson, and I. G. Colditz. 1999. The effect of dexamethasone on some immunological parameters in cattle. Vet. Res. Commun. 23:339-413.

Awawdeh, M. S., E. C. Titgemeyer, J. S. Drouillard, R. S. Beyer, and J. E. Shirley. 2007. Ruminal degradability and lysine bioavailability of soybean meals and effects on performance of dairy cows. J. Dairy Sci. 90:4740-4753.

Beerda, B., M. B. Schilder, N. S. Janssen, and J. A. Mol. 1996. The use of saliva cortisol, urinary cortisol, and catecholamine measurements for a noninvasive assessment of stress response in dogs. Horm. Behav. 30:272-279.

Blackburn, S. 1978. Amino Acid Determination: Methods and Techniques. 2nd ed. Marcel Dekker, New York, NY.

Blecha, F., S. L. Boyles, and J. G. Riley. 1984. Shipping suppresses lymphocyte blastogenesis responses in Angus and Brahman $\times$ Angus feeder calves. J. Anim. Sci. 59:576-583.

Chu, G. M., B. S. Yang, H. Y. Kim, J. H. Kim, J. H. Ham, C. H. Kim, S. D. Lee, and Y. M. Song. 2011. Effects of supplemental fermented agro by-products diet on the growth performances, blood characteristics and carcass traits in fattening pigs. Asian-australas. J. Anim. Sci. 24:1464-1472.

Church, J. S., and R. J. Hudson. 1999. Comparison of the stress of abrupt and interval weaning of farmed wapiti calves (Cervus elaphus). Small Rumin. Res. 32:119-124.

Conner, J. G., P. D. Eckersall, J. Ferguson, and T. A. Douglas. 1988. The acute phase response in the dog following surgical trauma. Res. Vet. Sci. 45:107-110.

Feng, J., X. Liu, Z. R. Xu, Y. P. Lu, and Y. Y. Liu. 2007. Effect of fermented soybean meal on intestinal morphology and digestive enzyme activities in weaned piglets. Dig. Dis. Sci. 52:1845-1850.

Fujiwara, K., Y. Miyaguchi, A. Toyoda, Y. Nakamura, M. Yamazaki, K. Nakashima, and H. Abe. 2008. Effect of fermented soybean "natto" supplement on egg production and qualities. Asian-australas. J. Anim. Sci. 21:1610-1615.

Heegaard, P. M. H., D. L. Godson, M. J. M. Toussaint, K. Tjørnehøj, L. E. Larsen, B. Viuff, and L. Rønsholt. 2000. The acute phase response of haptoglobin and serum amyloid A (SAA) in cattle undergoing experimental infection with bovine respiratory syncytial virus. Vet. Immunol. Immunopathol. 77:151-159.

Hickey, M. C., M. B. Drennan, and B. Earley. 2003. The effect of abrupt weaning of suckler calves on the plasma concentrations of cortisol, catecholamines, leukocytes, acute-phase proteins and in vitro interferon-gamma production. J. Anim. Sci. 81:2847-2855. 
Hong, K. J., C. H. Lee, and S. W. Kim. 2004. Aspergillus oryzae 3.042GB-107 fermentation improves nutritional quality of food soybean and feed soybean meals. J. Med. Food 7:430-435.

Jiang, R., X. Chang, B. Stoll, K. J. Ellis, R. J. Shypailo, E. Weaver, J. Campbell, and D. G. Burrin. 2000. Dietary plasma proteins used more efficiently than extruded soy protein for lean tissue growth in early-weaned pigs. J. Nutr. 130:2016-2019.

Kalavi, F. N. M., N. M. Muroki, A. M. Omwega, and R. K. N. Mwadime. 1996. Effect of tempe-yellow maize porridge and milk-yellow maize porridge on growth rate, diarrhoea and duration of rehabilitation of malnourished children. East Afr. Med. J. 73:427-431.

Kang, S.-Y., Y.-H. Ko, Y.-S. Moon, S.-H. Sohn, and I.-S. Jang. 2011. Effects of the combined stress induced by stocking density and feed restriction on hematological and cytokine parameters as stress indicators in laying hens. Asian-australas. J. Anim. Sci. 24:414420.

Karmini, M., E. Affandi, Hermana, D. Karyadi, and F. Winarno. 1997. The inhibitory effect of tempe on Escherichia coli infection. In Int. Tempe Symp. Indonesian Tempe Foundation, Bali, Indonesia.

Kiers, J. L., J. C. Meijer, M. J. R. Nout, F. M. Rombouts, M. J. A. Nabuurs, and J. Van Der Meulen. 2003. Effect of fermented soya beans on diarrhoea and feed efficiency in weaned piglets. J. Appl. Microbiol. 95:545-552

Kim, M. H., C. H. Yun, H. S. Kim, J. H. Kim, S. J. Kang, C. H. Lee J. Y. Ko, and J. K. Ha. 2010. Effects of fermented soybean meal on growth performance, diarrheal incidence and immune-response of neonatal calves. Anim. Sci. J. 81:475-481.

Kim, S. W., R. D. Mateo, and F. Ji. 2005. Fermented soybean meal as a protein source in nursery diets replacing dried skim milk. J. Anim. Sci. 83(Suppl. 1):116.

Lee, H. J. 1998. Health functional peptides from soybean foods. Korea Soybean Digest 15:16-22.

Li, D. F., J. L. Nelssen, P. G. Reddy, F. Blecha, J. D. Hancock, G. L. Allee, R. D. Goodband, and R. D. Klemm. 1990. Transient hypersensitivity to soybean meal in the early weaned pig. J. Anim. Sci. 68:1790-1799

Liu, X., J. Feng, Z. Xu, Y. Lu, and Y. Liu. 2007. The effects of fermented soybean meal on growth performance and immune characteristics in weaned piglets. Turk. J. Vet. Anim. Sci. 31:341-345.

Mackenzie, A. M., M. Drennan, T. G. Rowan, J. B. Dixon, and S. D. Carter. 1997. Effect of transportation and weaning on humoral immune responses of calves. Res. Vet. Sci. 63:227-230.
Marinkovic, S., G. P. Jahreis, G. G. Wong, and H. Baumann. 1989. IL6 modulates the synthesis of a specific set of acute phase proteins in vivo. J. Immunol. 142:808-812.

Min, B. J., J. H. Cho, Y. J. Chen, H. J. Kim, J. S. Yoo, Q. Wang, I. H. Kim, W. T. Cho, and S. S. Lee. 2009. Effects of replacing soy protein concentrate with fermented soy protein in starter diet on growth performance and ileal amino acid digestibility in weaned pigs. Asian-australas. J. Anim. Sci. 22:99-106.

Mjoun, K., K. F. Kalscheur, A. R. Hippen, and D. J. Schingoethe 2010. Ruminal degradability and intestinal digestibility of protein and amino acids in soybean and corn distillers grains products. J. Dairy Sci. 93:4144-4154.

Murata, H. 2007. Stress and acute phase protein response: An inconspicuous but essential linkage. Vet. J. 173:473-474.

Queyras, A., and M. Carosi. 2004. Non-invasive techniques for analysing hormonal indicators of stress. Ann. 1st Super. Sanita 40:211221

SAS Institute. 2001. SAS/STAT User's Guide. Version 8.2 ed. SAS Institute Inc., Cary, NC.

Sevi, A., L. Taibi, M. Albenzio, A. Muscio, S. Dell'Aquila, and F. Napolitano. 2001. Behavioral, adrenal, immune and productive responses of lactating ewes to regrouping and relocation. J. Anim. Sci. 79:1457-1465

Shan, T., Y. Wang, Y. Wang, J. Liu, and Z. Xu. 2007. Effect of dietary lactoferrin on the immune functions and serum iron level of weanling piglets. J. Anim. Sci. 85:2140-2146.

Wang, J. F., Y. H. Zhu, and D. F. Li. 2004. In vitro fermentation of various fiber and starch sources by pig fecal inocula. J. Anim. Sci. $82: 2615-2622$

Warren, E. J., B. N. Finck, S. Arkins, K. W. Kelley, R. W. Scamurra, M. P. Murthaugh, and R. W. Johnson. 1997. Coincidental changes in behavior and plasma cortisol in unrestrained pigs after intracerebroventricular injection of tumor necrosis factor- $\alpha$. Endocrinology 138:2365-2371.

Yoo, J. S., H. D. Jang, J. H. Cho, J. H. Lee, and I. H. Kim. 2009. Effect of fermented soy protein on nitrogen balance and apparent fecal and ileal digestibility in weaned pigs. Asian-australas. J. Anim. Sci. 22:1167-1173. 